\title{
Single cell genomic and transcriptomic evidence for the use of alternative nitrogen substrates by anammox bacteria
}

\author{
Sangita Ganesh $\mathbb{D}^{1,2}$ - Anthony D. Bertagnolli ${ }^{1}$. Laura A. Bristow ${ }^{3} \cdot$ Cory C. Padilla $^{1} \cdot$ Nigel Blackwood $^{4}$. \\ Montserrat Aldunate $\mathbb{1}^{5,6} \cdot$ Annie Bourbonnais ${ }^{7,8} \cdot$ Mark A. Altabet $^{8} \cdot$ Rex R. Malmstrom $^{9} \cdot$ Tanja Woyke $^{9}$. \\ Osvaldo Ulloa ${ }^{6} \cdot$ Konstantinos T. Konstantinidis $^{10} \cdot$ Bo Thamdrup $^{11}{ }^{11} \cdot$ Frank J. Stewart $^{1}$
}

Received: 12 October 2017 / Revised: 20 March 2018 / Accepted: 29 March 2018 / Published online: 10 July 2018

(c) International Society for Microbial Ecology 2018

\begin{abstract}
Anaerobic ammonium oxidation (anammox) contributes substantially to ocean nitrogen loss, particularly in anoxic marine zones (AMZs). Ammonium is scarce in AMZs, raising the hypothesis that organic nitrogen compounds may be ammonium sources for anammox. Biochemical measurements suggest that the organic compounds urea and cyanate can support anammox in AMZs. However, it is unclear if anammox bacteria degrade these compounds to ammonium themselves, or rely on other organisms for this process. Genes for urea degradation have not been found in anammox bacteria, and genomic evidence for cyanate use for anammox is limited to a cyanase gene recovered from the sediment bacterium Candidatus Scalindua profunda. Here, analysis of $\mathrm{Ca}$. Scalindua single amplified genomes from the Eastern Tropical North Pacific AMZ revealed genes for urea degradation and transport, as well as for cyanate degradation. Urease and cyanase genes were transcribed, along with anammox genes, in the AMZ core where anammox rates peaked. Homologs of these genes were also detected in meta-omic datasets from major AMZs in the Eastern Tropical South Pacific and Arabian Sea. These results suggest that anammox bacteria from different ocean regions can directly access organic nitrogen substrates. Future studies should assess if and under what environmental conditions these substrates contribute to the ammonium budget for anammox.
\end{abstract}

These authors contributed equally: Sangita Ganesh,

Anthony D. Bertagnolli.

Electronic supplementary material The online version of this article (https://doi.org/10.1038/s41396-018-0223-9) contains supplementary material, which is available to authorized users.

Frank J. Stewart

frank.stewart@biology.gatech.edu

1 School of Biological Sciences, Georgia Institute of Technology, Atlanta 30332 GA, USA

2 Radiant Genomics, Emeryville 94608 CA, USA

3 Biogeochemistry Group, Max Planck Institute for Marine Microbiology, Bremen, Germany

4 Department of Biology, University of Pennsylvania, Philadelphia 19104 PA, USA

5 Graduate Program in Oceanography, Department of Oceanography, Faculty of Natural Sciences and Oceanography, University of Concepción, Casilla 160-C, Concepción, Chile

\section{Introduction}

Anaerobic ammonium oxidation (anammox) plays a major role in aquatic nutrient cycling. In this microbial process, autotrophic bacteria oxidize ammonium with nitrite, producing energy for $\mathrm{CO}_{2}$ fixation and cellular growth, and $\mathrm{N}_{2}$ as an end product. Anammox is therefore a nitrogen

6 Departamento de Oceanografía, Universidad de Concepción, Casilla 160-C, Concepción 4070386, Chile

7 Marine Chemistry \& Geochemistry, Woods Hole Oceanographic Institution, 266 Woods Hole Road, Woods Hole 02543 MA, USA

8 School for Marine Science and Technology, University of Massachusetts Dartmouth, 706 Rodney French Blvd, New Bedford 02744 MA, USA

9 Department of Energy Joint Genome Institute, 2800 Mitchell Drive, Walnut Creek 94598 CA, USA

10 School of Civil and Environmental Engineering, Georgia Institute of Technology, Atlanta 30332 GA, USA

11 Department of Biology and Nordic Center for Earth Evolution (NordCEE), University of Southern Denmark, Odense, Denmark 
sink, converting bioavailable nitrogen to a gaseous form unavailable to most organisms. Anammox is particularly important in anoxic marine zones (AMZs) ([1-4]). In the major AMZs of the Eastern Tropical Pacific and Arabian Sea, dissolved oxygen is below detection $(<10 \mathrm{nM})$, nitrite is abundant (often $>5 \mu \mathrm{M}$ ), and anammox combined with heterotrophic denitrification drive nitrogen loss, with $\sim 20-40 \%$ of ocean nitrogen loss occurring in AMZs [5-10]. In these systems, anammox bacteria increase in abundance at anoxic depths, where ammonium is supplied by the mineralization of organic matter, yet concentrations are low and turnover and competition for this resource are high $[11,12]$. Under these conditions, anammox bacteria may be under pressure to use alternative substrates as ammonium sources, or potentially to use energy and biomass production pathways other than anammox. Indeed, in experimental studies of anammox in AMZs, the direct use of organics as a source of ammonium by anammox bacteria was proposed as an explanation for higher anammox rates in incubations with ${ }^{15} \mathrm{~N}$-nitrite compared to those with ${ }^{15} \mathrm{~N}$-ammonium, as the former would integrate $\mathrm{N}_{2}$ production from anammox based on all ammonium sources [13, 14]. However, the metabolic versatility of marine anammox bacteria remains largely unknown. This is due in part to limited genomic characterizations of anammox bacteria from diverse marine habitats, including AMZs.

Anammox has thus far been described only in bacteria of the Order Brocadiales in the phylum Planctomycetes. This Order occurs globally in natural and man-made environments in both fresh and saltwater. No Brocadiales bacteria have yet been isolated in pure culture. The known diversity of this group is distributed across the Candidatus genera Brocadia, Kuenenia, Anammoxoglobus, Jettenia, and Scalindua. Of these, $\mathrm{Ca}$. Scalindua is the dominant genus in ocean habitats, including sediments and AMZs [12, 15], but has also been found in freshwater [16]. Insight into the genomic potential of $\mathrm{Ca}$. Scalindua is based on metagenomic contigs of $\mathrm{Ca}$. S. profunda from marine sediment [17], Ca. S. brodae from a wastewater plant [18], and $C a$. S. rubra from a marine brine pool [19]. These large genomes (>4000 genes; $\sim 4-5.2 \mathrm{Mbp}$ ) contain many genes absent from characterized genomes of other anammox genera, but also vary in gene content among species. For example, of these three species, only $\mathrm{Ca}$. S. rubra contains genes for gas vesicle biosynthesis, presumably as an adaptation for regulating position in brine pools. However, genomes of $\mathrm{Ca}$. Scalindua cells from AMZs have not yet been reported. Our knowledge of gene content in $\mathrm{Ca}$. Scalindua from AMZs is based on recruitment of meta-omic sequences to non-AMZ genomes, e.g., of $\mathrm{Ca}$. Scalindua profunda $[5,17,20]$. We therefore have limited understanding of how anammox bacteria may be adapted to AMZ conditions.
The waste product urea $\left(\mathrm{CO}\left(\mathrm{NH}_{2}\right)_{2}\right)$ and its breakdown product cyanate $\left(\mathrm{OCN}^{-}\right)$are potential alternative substrates for anammox bacteria. Urea is ubiquitous in ocean waters, originating from microbial degradation of dissolved organic matter and nitrogenous waste from microbes and animals [21]. Diverse microorganisms produce urease enzymes that hydrolyze urea to ammonia and $\mathrm{CO}_{2}$, potentially to aid $\mathrm{pH}$ regulation or to acquire ammonia for biomass production or energy generation [22]. Ureases have even been found in aerobic ammonia-oxidizing bacteria [23] and archaea [24, 25], as well as nitrite-oxidizing bacteria [26], suggesting that organic nitrogen plays a role in nitrification. Indeed, certain aerobic ammonia-oxidizing bacteria not only oxidize ammonia derived from urea, but also assimilate the $\mathrm{CO}_{2}$ resulting from urease activity [27]. Recently, anammox bacteria from the Eastern Tropical South Pacific (ETSP) AMZ were shown to produce $\mathrm{N}_{2}$ from added urea, but only after a lag of 1.5 days [28]. This was interpreted as evidence that anammox bacteria do not degrade urea directly but instead rely on the urealytic activity of other organisms or on abiotic urea degradation to supply ammonium. An inability of anammox bacteria to directly degrade urea is supported by the absence of urease-encoding genes (ure) in available anammox genomes.

In contrast to urea, cyanate addition stimulated $\mathrm{N}_{2}$ production by anammox without a lag phase in incubations of AMZ water [28]. This suggests that AMZ anammox bacteria might use cyanate directly, presumably though conversion to ammonia and $\mathrm{CO}_{2}$ by a cyanase enzyme, with the resulting ammonium used for anammox. Although absent from draft genomes of other $\mathrm{Ca}$. Scalindua species [19], a putative cyanase-encoding gene $(c y n S)$ is present in the metagenome of $\mathrm{Ca}$. S. profunda from sediment [17], and sequences related to this gene were detected in AMZ metagenomes and metatranscriptomes [28]. However, data conclusively linking cyanases to anammox bacterial genomes from AMZs are not yet available, and it is therefore unknown if these bacteria might also rely on other microbes for cyanate degradation, as has been shown for certain aerobic ammonia oxidizers [29].

Here, we explored the metabolic properties of $\mathrm{Ca}$. Scalindua sp. from a marine AMZ, testing the hypothesis that these bacteria have the potential for directly catabolizing organic nitrogen substrates as ammonium sources for anammox. We explored this hypothesis using genomes of $\mathrm{Ca}$. Scalindua cells from the Eastern Tropical North Pacific (ETNP) AMZ off Mexico. These genomes were then analyzed in conjunction with ETNP chemical concentration, anammox rate, and metatranscriptome data from a cruise in 2014. The results provide insight into the genetic basis for environmental variation and adaptation in this globally important lineage. 


\section{Materials and methods}

\section{Sample collection}

Samples for single amplified genome (SAG) analysis were collected in 2013 from station $6 \mathrm{~T}\left(18^{\circ} 54.0 \mathrm{~N}, 104^{\circ}\right.$ $54.0 \mathrm{~W}$; Fig. S1) in the ETNP AMZ during the Oxygen Minimum Zone Microbial Biogeochemistry Expedition (OMZoMBiE) cruise ( $R / V$ New Horizon; 13-28 June). Seawater for cell sorting and SAG sequencing was collected from the secondary nitrite maximum $(125 \mathrm{~m})$ and $\mathrm{AMZ}$ core $(300 \mathrm{~m})$ using Niskin bottles on a rosette containing a Conductivity-Temperature-Depth profiler (Sea-Bird SBE 911plus). From each depth, triplicate $1 \mathrm{ml}$ samples of bulk seawater (no pre-filtration) were aliquoted into sterile cryovials and $100 \mu \mathrm{l}$ of a glycerol TE stock solution $(20 \mathrm{ml}$ $100 \times \mathrm{TE} \mathrm{pH} 8.0,60 \mathrm{ml}$ deionized water, $100 \mathrm{ml}$ glycerol) was added to each vial. The vials were then mixed and frozen at $-80^{\circ} \mathrm{C}$.

Samples for metatranscriptome analysis and measurements of anammox rates were collected from the ETNP AMZ during a second OMZoMBiE cruise, in $2014(R / V$ New Horizon; 10 May-8 June, 2014). Water was collected at six stations spanning a coastal to offshore gradient (Fig. S1). Stations and depths sampled for metatranscriptomics $(n=21)$ are in Table S1. Eight of the 21 metatranscriptome datasets were generated in this study; the remainder were generated in two prior studies [30, 31] and re-analyzed here. Seawater was collected by Niskin with microbial biomass then collected by in-line filtration of seawater $(\sim 1.5-2.5 \mathrm{~L})$ through a glass fiber disc prefilter (GF/A, $47 \mathrm{~mm}, 1.6 \mu \mathrm{m}$ pore-size, Whatman) and a primary collection filter (Sterivex ${ }^{\mathrm{TM}}, 0.22 \mu \mathrm{m}$ pore-size, Millipore) using a peristaltic pump. Sterivex ${ }^{\mathrm{TM}}$ filters were filled with RNA stabilizing buffer $(25 \mathrm{mM}$ sodium citrate, $10 \mathrm{mM}$ EDTA, 5.3 M ammonium sulfate, $\mathrm{pH}$ 5.2), flash-frozen in liquid nitrogen, and stored at $-80{ }^{\circ} \mathrm{C}$. Approximately 15-45 min elapsed (depending on depth) between capture in the Niskin and arrival on deck; 20 min elapsed between water retrieval from the Niskin and fixation of filters in buffer.

Ammonium concentrations were determined fluorometrically aboard ship using the orthophaldialdehyde method [32], with a detection limit of $10 \mathrm{nM}$. Samples for measuring nitrite concentrations were collected in acid-cleaned HDPE bottles and stored frozen until spectrophotometric measurement using the Griess method [33] with a Westco SmartChem 200 (Unity Scientific). On a cruise to the study area in 2017 ( $R / V$ Oceanus cruise OC1705), urea concentrations were determined fluorometrically following Mulvenna and Savidge [34] with a $5 \mathrm{~cm}$ cuvette. This method has a detection limit of $45 \mathrm{nM}$.
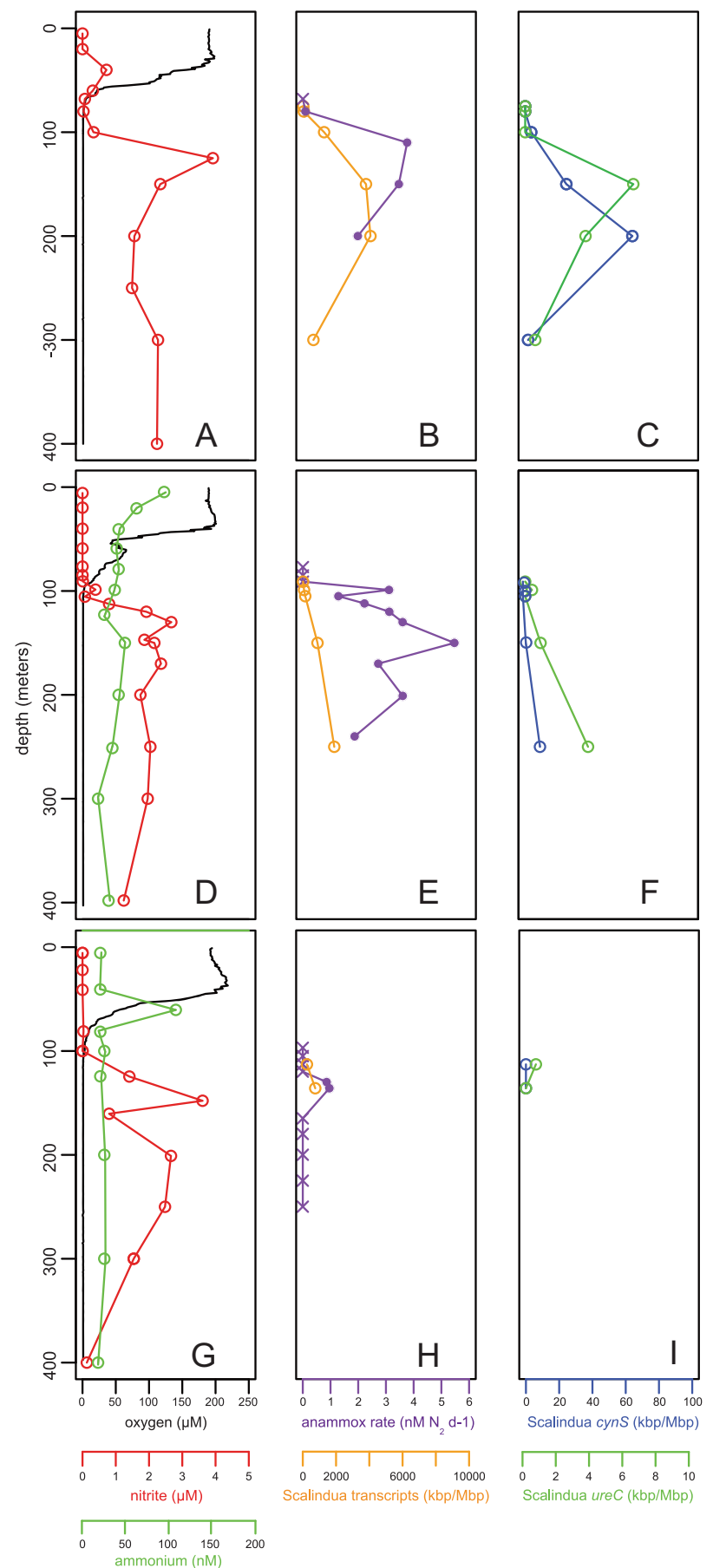

Anammox rate measurements

Anammox rates were measured for 14 of the 21 water samples from which metatranscriptomes were generated (Fig. 1, S2, Table S1). Water was sampled directly from the Niskin and transferred to $250 \mathrm{ml}$ glass bottles without pre-filtration. Bottles were overflowed (three volume equivalents) and sealed without bubbles with deoxygenated butyl rubber stoppers to minimize oxygen contamination (following [13]). Within $6 \mathrm{~h}$ of collection, each bottle was amended with $5 \mu \mathrm{M}{ }^{15} \mathrm{NH}_{4}+$, and purged with helium for 
Fig. 1 Anammox rates and representation of ETNP $\mathrm{Ca}$. Scalindua transcripts relative to dissolved oxygen, ammonium, and nitrite concentrations at three ETNP stations: $6(\mathbf{a}-\mathbf{c}), 7(\mathbf{d}-\mathbf{f})$, and $3(\mathbf{g}-\mathbf{i})$. The first column displays dissolved oxygen (black line, $\mu \mathrm{M}$ ), nitrite (red circles and line, $\mu \mathrm{M}$ ), and ammonium (green circle and line, $\mathrm{nM}$ ). An ammonium profile at station 6 showed concentrations consistently above $140 \mathrm{nM}$, which is inconsistent with all other stations sampled and with AMZ literature to date. We therefore interpret this signal as potential contamination and have excluded these data. The second column displays anammox rates (purple line and circles) and the cumulative contribution of all transcripts recruiting to ETNP $\mathrm{Ca}$. Scalindua (orange circle and lines, $\mathrm{kbp} / \mathrm{Mbp}$ ). Purple crosses denote non-significant rates. Transcript representation is calculated as lengthcorrected kilobase pairs of transcripts mapping (via BLASTX, with bit score $>50$ and AAI $>95 \%$ ) to a composite ETNP $\mathrm{Ca}$. Scalindua SAG database, per Megabase pairs sequenced. The third column designates the activity and distribution of cyanate hydratase $(c y n S)$ and urease (ure $C$ ) transcripts associated with ETNP $\mathrm{Ca}$. Scalindua. For all rows, the $y$-axis indicates water column depth. SAG samples were collected from 125 to $300 \mathrm{~m}$ at station 6 in 2013

$\sim 20 \mathrm{~min}$. With a slight overpressure, water was dispensed into $12 \mathrm{ml}$ exetainers (Labco, Lampeter, Ceredigion, UK), which were immediately capped with deoxygenated lids. Headspaces of $2 \mathrm{ml}$ were introduced into each exetainer and flushed twice with helium, with shaking between flushings. Exetainers were then incubated in the dark at in situ temperature $\left(13^{\circ} \mathrm{C}\right)$ for $24 \mathrm{~h}$. For each sample, triplicate exetainers were preserved with $100 \mu \mathrm{l}$ of $50 \%$ (w/v) $\mathrm{ZnCl}_{2}$ at the start of the incubation and again after $24 \mathrm{~h}$.

Production of ${ }^{14} \mathrm{~N}^{15} \mathrm{~N}$ and ${ }^{15} \mathrm{~N}^{15} \mathrm{~N}$ was determined on a gas chromatography isotope ratio mass spectrometer (GCIRMS) as in Dalsgaard et al. [1]. Rates of $\mathrm{N}_{2}$ production by anammox were calculated as in Thamdrup and Dalsgaard [35] from the slope of the linear regression of ${ }^{14} \mathrm{~N}^{15} \mathrm{~N}$ with time. $t$-tests were applied in all cases to determine whether rates were significantly different from zero $(p<0.05)$.

\section{SAG generation and taxonomic screening}

SAGs were generated from individual bacterial cells according to the Department of Energy Joint Genome Institute workflow following Rinke et al. [36, 37] with minor modifications (as in ref. [38]). Cells were sorted on a BD Influx (BD Biosciences) and treated with Ready-Lyse lysozyme (Epicentre; $5 \mathrm{U} / \mu \mathrm{L}$ final conc.) for $15 \mathrm{~min}$ at room temperature prior to adding lysis solution. Whole genomes were amplified by multiple displacement amplification (MDA) using the REPLI-g Single Cell Kit (Qiagen), with final reaction volumes of $2 \mu \mathrm{L}$ and termination after $6 \mathrm{~h}$. The taxonomic identity of each SAG was determined by PCR amplification and Sanger sequencing of a $\sim 470 \mathrm{bp}$ region of the 16S rRNA gene using primers $926 \mathrm{wF}$ ( $5^{\prime}$-AAACT YAAAKGAATTGRCGG- $3^{\prime}$ ) and $1392 \mathrm{R}$ (5'-ACGGG CGGTGTGTRC- $3^{\prime}$ ) for archaea and bacteria. Recovered sequences (average length: $423 \mathrm{bp}$ ) were classified using MOTHUR's 'classify_seq' against the Greengenes database, with the probability of correct assignment to a taxonomic group calculated using the naïve Bayesian classifier method [39].

\section{SAG sequencing}

In total 20 SAGs classified with high confidence as belonging to the genus $\mathrm{Ca}$. Scalindua were selected for genome sequencing. These included 9 and 11 SAGs from $125 \mathrm{~m}$ and $300 \mathrm{~m}$, respectively. Indexed DNA sequencing libraries were prepared using the Nextera XT DNA Library Prep kit (Illumina, San Diego, CA, USA) following manufacturer instructions, pooled, and sequenced on an Illumina MiSeq using a v2-500 cycle (paired end $250 \times 250 \mathrm{bp}$ ) kit.

\section{RNA extraction and CDNA sequencing}

RNA was extracted from Sterivex ${ }^{\mathrm{TM}}$ filters as in Ganesh et al. [5] using a modification of the mirVana ${ }^{\mathrm{TM}}$ miRNA Isolation kit (Ambion). Filter cartridges were thawed on ice, and RNA stabilizing buffer was expelled by syringe from each cartridge and discarded. Cells were lysed by adding Lysis buffer and miRNA Homogenate Additive (Ambion). Following vortexing and incubation on ice, lysates were transferred to RNAase-free tubes and RNA extracted by acid phenol:chloroform according to the kit. The TURBO DNA-free ${ }^{\mathrm{TM}}$ kit (Ambion) was used to remove DNA and the extract purified using the RNeasy MinElute Cleanup Kit (Qiagen). RNA was prepared for sequencing using the ScriptSeqTM v2 RNA-Seq Library preparation kit (Epicentre). cDNA was synthesized from fragmented total RNA (rRNA not removed) using reverse transcriptase and amplified and barcoded using ScriptSeq ${ }^{\mathrm{TM}}$ Index PCR Primers (Epicenter) to generate single-indexed libraries. cDNA libraries were pooled and sequenced on an Illumina MiSeq using a v2-500 cycle (paired end $250 \times 250$ bp) kit.

\section{SAG assembly, quality control, and sequence analysis}

Illumina reads were filtered for quality using a Phred score cutoff of 25 and trimmed using TrimGalore (http://www. bioinformatics.babraham.ac.uk/projects/trim_galore/). High quality paired reads were merged using FLASH [40]. Quality-trimmed merged and unmerged reads were combined and assembled using the SPAdes assembler [41] with k-mer sizes of $21,33,55,77,99,127$, and the single-cell (-sc) option. Coding sequences were predicted using GeneMark. hmm [42], and 16S rRNA gene sequences were identified using RNAmmer [43], both using default parameters. Percentage of contamination and genome completeness were assessed based on detecting lineage-specific marker genes using CheckM [44]. 
Full-length (>1500 bp) 16S rRNA gene sequences were detected on 8 SAGs. These sequences were imported into the ARB environment [45] and placed within the ARB backbone tree using the parsimony tool. Brocadialesassociated 16S rRNA genes from Woebken et al. [12] and Galan et al. [46] were imported for comparative purposes to assign SAG 16S rRNA genes to previously reported subclades of marine $\mathrm{Ca}$. Scalindua. Additional sequences from Schmid et al. [47], representing species-level Candidatus Scalindua designations, were also included as outgroups to the "Arabian Sea" sequence cluster (see Results below). Sequence alignments were created using the automated aligner, then manually curated when needed. To assess the 16S rRNA gene phylogeny using only informative positions, a mask was created based on the curated alignment, and used for construction of Neighbor-Joining (with Feldstein correction), Maximum Likelihood (with LG substitution model), and Parsimony trees with 1000 bootstraps for all models.

All SAG-associated assemblies generated from MDA products were analyzed using Prokka [48]. The "faa" files from this pipeline were used as queries for BLASTP searches against public and custom databases (described below). For visualization of gene order and synteny, contigs with features of interest were extracted from the "gbk" files from Prokka. Contigs of interest were then imported into "EasyFig" and compared to one another using BLASTN. The associated output figures were manually curated in Adobe Illustrator. The package T-REKs [49] was used to identify tandem repeats on contigs of interest.

Predicted amino acid sequences from 6 SAGs were used to create a composite SAG database for comparison against public databases using BLASTP and for use as a reference database for BLASTX-based analyses of metagenomes and metatranscriptomes (described below). Our goal in creating this database was to capture the majority of functional gene content across the SAGs (related to one another at roughly the species level; see Results), rather than to resolve population-level variation among the SAGs. The 6 SAGs were chosen because they had relatively high completeness $(28.2-50.0 \%)$, minimal contamination $(<5 \%)$, and fulllength 16S rRNA gene sequences. SAG sequences were clustered (using UCLUST and USEARCH commands) at $50 \%$ amino acid identity (AAI). Clustering yielded 2703 proteins, including 49 of the 54 universally conserved single-copy ribosomal proteins [50]. This result suggested that the composite database was $\sim 91 \%$ complete (based only on universal marker gene recovery) and that a complete composite database would contain $~ 3000$ proteincoding genes (50\% AAI clusters), roughly consistent with genome size estimates based on individual SAGs (extrapolated using estimated genome completeness and counts of detected genes per SAG; Table 1).
A custom database of protein sequences from anammox taxa was created for comparison to the SAG gene set. Anammox-associated genomes were identified in NCBI using the search term "Brocadiales". All amino acid sequences $(n=50,272)$ from these genomes were downloaded and combined with amino acid sequences $(n=4330)$ from $\mathrm{Ca}$. Scalindua profunda (obtained according to [17]), yielding a database of 54,602 proteins. SAG proteins were then queried against this database via BLASTP. A sequence was considered unique to the SAG set if this query did not return a significant match (bit score $>50$ ) to a database sequence. Using this method, all urea-associated proteins (urease and accessory proteins) were identified as unique to the ETNP SAG set, along with 1803 other genes (1811 total unique). Of the other genes unique to ETNP SAGs, 1604 encoded hypothetical proteins. Non-hypothetical, unique protein-coding genes are listed in Table S2.

To further assess relatedness among SAGs, average nucleotide identity (ANI) and average amino acid identity (AAI) between each pair of SAGs was calculated using the ani.rb and aai.rb scripts from the enve-omics toolkit [51] with ani.rb cutoffs of $700 \mathrm{bp}$ minimum alignment length and $70 \%$ minimum identity, and aai.rb cutoffs of bit score $>50$ and $90 \%$ minimum alignment length (as a fraction of the shorter sequence). The get_homologues package [52] was used to identify genes shared between each SAG and protein-coding sequences in the $\mathrm{Ca}$. Scalindua profunda genome.

\section{Metatranscriptome analysis}

Metatranscriptomic reads were trimmed and merged as above for SAG sequences. Merged reads were compared to the SILVA rRNA database using BLASTN, and sequences with significant matches to rRNA genes were identified and removed. Non-rRNA reads were queried (BLASTX) against the composite database (see above). BLAST output was parsed to identify transcripts recruiting to SAGs with bit score $>50$ and AAI $>95 \%$. Counts of mapped transcripts per gene were normalized by gene length and sequencing depth, with final counts expressed as kilobase pairs of mapped transcripts per Megabase pairs sequenced.

\section{Screening of $A M Z$ metagenomes and metatranscriptomes}

Publically available metagenomes and metatranscriptomes from the ETSP AMZ and metagenomes from the Arabian Sea and Saanich Inlet AMZs were screened for close homologs of SAG ure and cyn genes (Table 2). Sequences first were compared to the SILVA rRNA database using BLASTN, and sequences identified as rRNA genes/transcripts were removed. Remaining reads were compared 


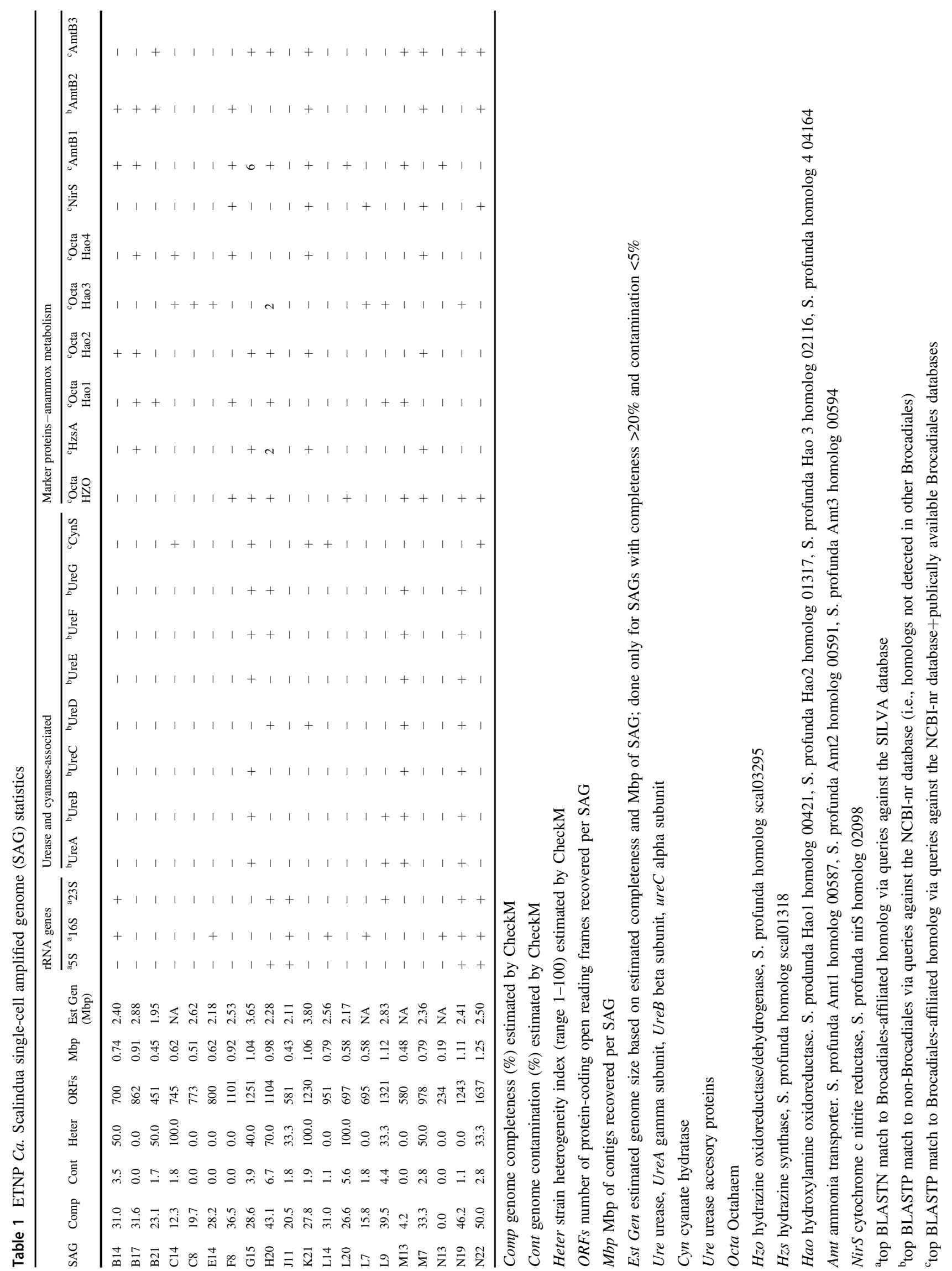


using BLASTX against a database of the urease and cyanase-encoding genes recovered from the ETNP SAGs, using match thresholds of bit score $>50$ and AAI $>95 \%$. To test for the presence of SAG urease genes in the ETNP community, we screened a deeply sequenced (HiSeq) metagenome from 200 meters at station $6 \mathrm{~T}$ against a 39,476 bp ure-containing SAG contig using BLASTN. This metagenome was trimmed and cleaned as in [53] and binned using MetaBat [54]. Genes recovered on the assembled contigs of the aforementioned metagenome were also compared by BLASTX against a custom database containing the SAG urease genes and 2870 ureC genes available in NCBI's protein database (as of 01-03-2018), using the match parameters described above. The taxonomic identities of top matching database entries were used to estimate the taxonomic richness of ureases in the OMZ community. We did not screen for $\mathrm{Ca}$. Scalindua-like cynS genes, as these have been previously reported in Eastern Pacific AMZ meta-omic datasets [28].

All sequence data generated in this study are in NCBI under BioProject PRJNA407229.

\section{Results and Discussion}

\section{Hydrographic conditions and anammox activity in the ETNP AMZ}

Figure 1 shows data from the three most extensively sampled ETNP stations, including two near-shore stations $(6 \mathrm{~T}, 7 \mathrm{~T})$ and a station $(3 \mathrm{~T})$ farther offshore; data from three additional stations are in Fig. S2, with station coordinates in Table S1. At all stations, anoxic conditions were observed from depths of $\sim 70-100 \mathrm{~m}$. Nitrite concentration was near the detection limit in the surface layer, but increased directly below the oxic-anoxic interface to 3-5 $\mu \mathrm{M}$, a characteristic feature of AMZs. Ammonium concentrations were generally in the low nanomolar range (20-50 nM) (Fig. 1, S2). Neither cyanate nor urea was measured on the 2014 cruise. However, in samples from a 2017 cruise along the same transect, urea concentration was below the detection limit within the AMZ, but above detection in the mixed layer, reaching maxima of $\sim 100 \mathrm{nM}$ (data not shown).

Anammox rates varied over depth and with proximity to shore. Measured rates were highest in the upper AMZ, increasing sharply below the oxic-anoxic interface with near-maximal rates reached only 10-20 m deeper (Fig. 1, S2). Rates were lowest and confined to a narrow depth range at station $3 \mathrm{~T}$ farthest from shore (up to $1 \mathrm{nM} \mathrm{N}_{2} \mathrm{~d}^{-1}$ ), with rates increasing to $5.5 \mathrm{nM} \mathrm{N}_{2} \mathrm{~d}^{-1}$ at the near-shore sites (6 T, $7 \mathrm{~T}$; Fig. 1). This is consistent with analyses in the ETSP AMZ off Chile and Peru, which showed anammox rates to be highest in shelf waters and to diminish with distance from shore, strongly correlating with organic matter export [11]. Our measured rates are similar to those measured previously at sites close to ours in the ETNP [5, 55] and at other open ocean AMZ sites [56].

\section{Genomic evidence for organic nitrogen utilization in ETNP Ca. Scalindua}

Ca. Scalindua bacteria in AMZs may contain metabolic features distinct from those of anammox bacteria in other environments. We explored this potential by analyzing 20 SAGs from two anoxic depths at station $6 \mathrm{~T}$ in the ETNP. All 20 SAGs were classified with high confidence (Probability score $=100.0$, Naïve Bayesian classifier) as $C a$. Scalindua sp. based on PCR-amplified 16S rRNA gene fragments.

As is common in single-cell analysis [36, 57], estimated genome completeness and strain heterogeneity varied considerably among the SAGs (range: $0-50 \%$ and $0-100 \%$, respectively; average: $27.4 \%$ and $33.0 \%$ ). However, contamination was consistently low (average: $2.0 \%$ ) and in some cases non-detectable, with moderate levels $(>5 \%)$ in only two SAGs (Table 1). Based on genome completeness and total recovered sequence length, estimated genome size averaged 2.6 Mbp (range: $2.0-3.8 \mathrm{Mbp}$ ). The SAG with the highest estimated completeness (50\%, SAG N22) contained 1637 protein-coding genes, suggesting a total gene count $(\sim 3300)$ smaller than that of $\mathrm{Ca}$. Scalindua genomes of other species (>4000 genes). On average, regions homologous between SAGs shared $94.1 \%$ ANI (standard deviation: 2.7) and homologous open reading frames shared $85.3 \%$ AAI (standard deviation: 3.8) among SAGs and 73\% AAI with homologs from $\mathrm{Ca}$. Scalindua profunda, a sediment anammox bacterium with a near complete ( $>90 \%)$ genome. Analysis of diverse bacteria shows that strains of the same species generally share $>94 \%$ ANI [58], whereas the AAI value observed here falls at the lower end of the estimated species boundary [59]. Full-length ( $>1500 \mathrm{bp}$ ) 16S rRNA genes were identified in 8 SAGs ( 1 from $125 \mathrm{~m}, 7$ from $300 \mathrm{~m}$ ), shared $98-100 \%$ ANI, and were identical or nearly identical to the $16 \mathrm{~S}$ rRNA gene fragments obtained from all SAGs by PCR-based screening (Fig. S3). These 8 full-length 16S rRNA sequences clustered in a monophyletic sub-clade of $\mathrm{Ca}$. Scalindua referred to as the Arabian Sea cluster and were nearly identical to clones primarily from the AMZ in the Arabian Sea [12], but more distantly related to a cluster of $\mathrm{Ca}$. Scalindua sequences from the ETSP AMZ off Peru and Chile (Fig. 2). Together, these data suggest high relatedness among the analyzed cells, which cluster within a $\mathrm{Ca}$. Scalindua clade distributed widely across diverse AMZs.

Protein-coding genes in the SAGs, hereafter referred to as ETNP $\mathrm{Ca}$. Scalindua, were compared against a database of 
Table 2 Detection of ETNP $\mathrm{Ca}$. Scalindua urease and cyanase genes in diverse AMZ datasets

\begin{tabular}{|c|c|c|c|c|c|c|c|c|c|c|c|}
\hline SRA identifier & DNA/RNA & Environment & Reads $^{\mathrm{a}}$ & ureA & ureB & ureC & ureD & ureE & ureF & ureG & cynS \\
\hline SRX025906 & DNA & $50 \mathrm{~m}$, oxycline, Chile, 2008 & 393403 & - & - & - & - & - & - & - & - \\
\hline SRX025907 & RNA & 50 m, oxycline, Chile, 2008 & 379333 & - & - & - & - & - & - & - & - \\
\hline SRX025908 & DNA & $85 \mathrm{~m}$, base of oxycline, Chile, 2008 & 595662 & - & - & - & - & - & - & - & - \\
\hline SRX025909 & RNA & $85 \mathrm{~m}$, base of oxycline, OMZ, Chile, 2008 & 142020 & - & - & - & - & - & - & - & - \\
\hline SRX025910 & DNA & $110 \mathrm{~m}$, upper anoxic OMZ, Chile, 2008 & 197843 & - & - & - & 1 & - & - & 1 & - \\
\hline SRX025911 & RNA & $110 \mathrm{~m}$, upper anoxic OMZ, Chile, 2008 & 514076 & 1 & - & 2 & 1 & - & - & - & - \\
\hline SRX025912 & DNA & $200 \mathrm{~m}$, anoxic OMZ core, Chile, 2008 & 516426 & - & 4 & 8 & 10 & 6 & 5 & 6 & 2 \\
\hline SRX025913 & RNA & $200 \mathrm{~m}$, anoxic OMZ core, Chile, 2008 & 441273 & - & 1 & 2 & - & 2 & - & 2 & 4 \\
\hline SRX080956 & DNA & $50 \mathrm{~m}$, oxycline, Chile, 2010 & 1534798 & - & - & - & - & - & - & - & - \\
\hline SRX080960 & DNA & $110 \mathrm{~m}$, upper anoxic OMZ, Chile, 2010 & 1459563 & 1 & - & 1 & 2 & 2 & - & 2 & \\
\hline SRX080955 & DNA & 110 m, upper anoxic OMZ, Chile, 2009 & 917531 & 1 & - & - & 1 & - & - & - & 1 \\
\hline SRR070082 & DNA & $200 \mathrm{~m}$, anoxic OMZ core, Chile, 2009 & 930936 & 1 & 1 & 1 & 2 & 2 & 1 & 1 & 1 \\
\hline SRR2657589 & DNA & 600 m, anoxic OMZ core, Arabian Sea, 2009 & 2588720 & 2 & 0 & 2 & 3 & 1 & 1 & 0 & - \\
\hline SRX1878045 & RNA & $200 \mathrm{~m}$, anoxic seasonal OMZ, Saanich Inlet & 69907523 & - & - & - & - & - & - & - & - \\
\hline
\end{tabular}

${ }^{\mathrm{a}}$ Total number of sequence fragments in dataset

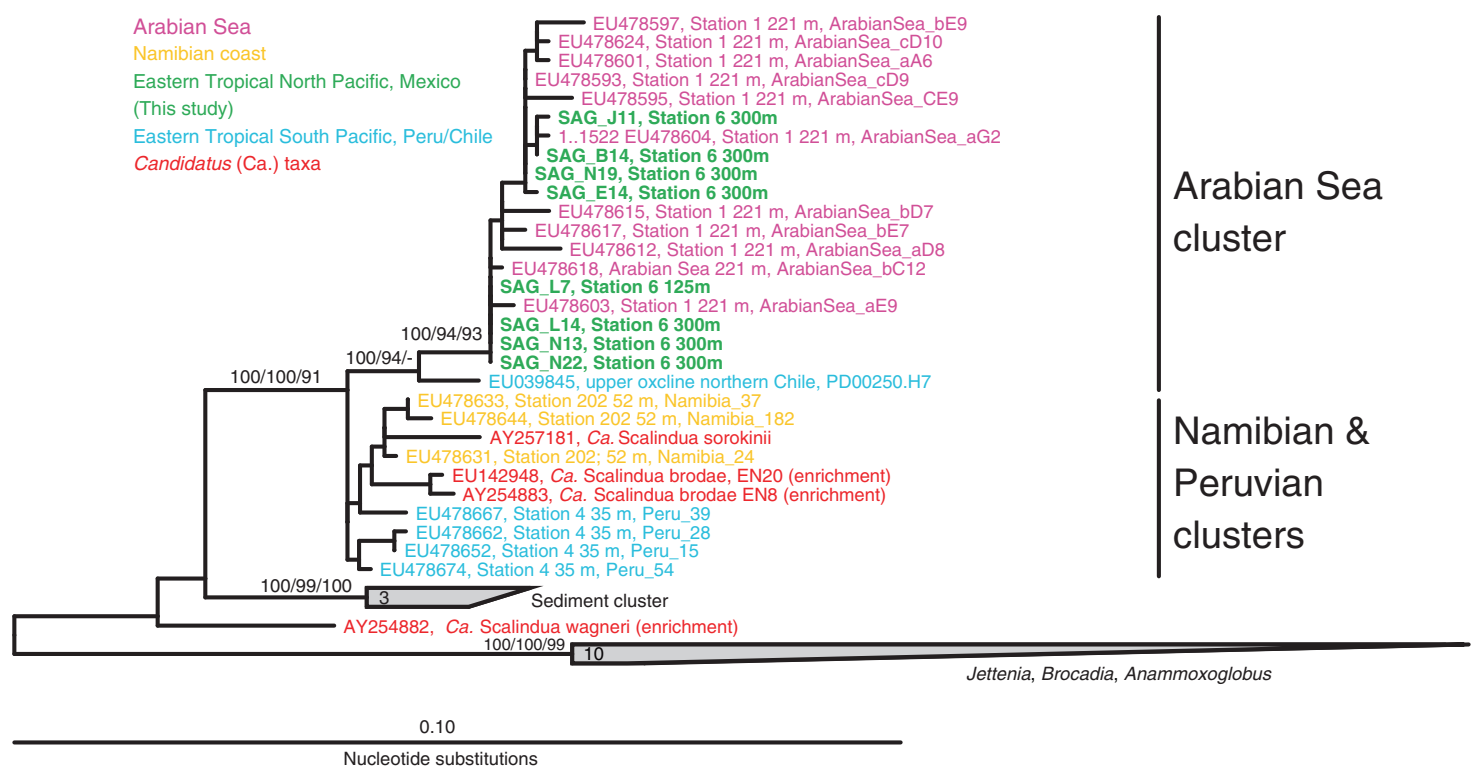

Fig. 2 16S rRNA gene-based phylogenetic placement of 8 ETNP $\mathrm{Ca}$. Scalindua-related SAGs from two anoxic depths in the ETNP AMZ. Full length (>1500 bp) 16S rRNA genes were identified in SAGs using RNAmmer, and characterized phylogentically relative to database sequences. The phylogeny was estimated using maximum likelihood

amino acid sequences from all available anammox-associated genomes. Genes diagnostic of the anammox process encoding hydrazine synthase (HZS), hydrazine oxidase/dehydrogenase (HZO), and $c d_{l}$ nitrite:nitric oxide oxidoreductase (NirS) were found in 5,8 , and 6 of the 20 SAGs, respectively (Table 1), confirming the metabolic role of these bacteria. Genes encoding octahaem hydroxylamine oxidoreductases (HAO) and ammonium transporters (Amt), both of which are observed in multiple copies in anammox genomes, were in ARB with boot strap values based on Neighbor joining, maximum likelihood, and maximum parsimony using 1000, 100, and 1000 bootstrap re-samplings, respectively. Maximum likelihood support values are based on approximate likelihood Bayesian ratios ('abayes')

identified in 16 and 15 of the SAGs, respectively. Amino acid sequences of HZS, HZO, NirS, HAO, and two of the three Amt proteins displayed highest scoring matches to homologs from other anammox bacteria when queried (BLASTP) against the NCBI nr database. Together, the recovery of multiple genes of anammox central metabolism and the shared ancestry of these genes with other Brocadiales identifies the SAGs as members of the AMZ anammox community. 
Comparative analyses revealed 1811 non-redundant genes (out of 14,610 total (redundant/non-redundant) across the SAGs) that did not have a significant (bit score $>50$, BLASTP) match to a protein sequence in the custom database, and therefore may be unique to the ETNP $\mathrm{Ca}$. Scalindua group. This "unique" gene set is dominated by uncharacterized hypothetical proteins (1569 of 1811, 86\%), consistent with high proportions of uncharacterized lineage-specific genes in other anammox genomes [19]. A total of 206 non-redundant proteins displayed significant matches to the COG database via BLASTP, while 36 displayed an identifiable protein domain structure but did not display significant similarity to the COG database (Table S2).

Of the unique classifiable sequences, we focused on those that allowed us to explore the hypothesis of alternative nitrogen substrate use. In contrast to all characterized genomes of anammox bacteria, ETNP $C a$. Scalindua SAGs contain genes for hydrolysis and transport of urea (Table 1, Fig. 3a). In three SAGs (G15, M13, N19), we identified contigs containing ureC encoding the alpha subunit of urease, the nickel (Ni)containing enzyme that facilitates cleavage of urea into ammonia and carbamate [60], with the carbamate then spontaneously forming ammonia and carbon dioxide. The ETNP Ca. Scalindua ureC encodes conserved catalytic site residues present in enzymatically verified UreC of urease-positive bacteria (Fig. S4) and is directly downstream of genes for the non-catalytic gamma and beta urease subunits and directly upstream of genes encoding urease accessory proteins UreEFG required for assembly and activation of the apoprotein (Fig. 3). This gene order is nearly identical to that observed in enzymatically verified urease-positive bacteria (e.g., Proteus mirabilis; [61]. Studies using ure knockout mutants indicate that UreE is likely the $\mathrm{Ni}$ donor, while UreF and UreG are chaperones enabling $\mathrm{Ni}$ donation from UreE [60]. The ureD gene, which encodes a fourth subunit whose function is unclear but is required for urease assembly in $P$. mirabilis, was identified downstream of ure $G$ on one of the ure $C$-containing contigs, and on separate, smaller contigs in other SAGs. Genes encoding high affinity ABC-type urea transporters (urtCDE, Fig. 3) are also present on the ure-containing contigs of SAGs $\mathrm{N} 19$ and M13. The urease-associated genes (ure and urt) show $\geq 98 \%$ ANI among SAGs, with the vast majority of mutations at the third codon position. The sequences from one SAG (G15) are nearly identical to those from an assembled metagenome contig from the AMZ core (JGI Scaffold in Fig. 3a), confirming the presence of these genes in community data from the site. However, SAG-affiliated ure genes $($ ureC) were at low proportional abundance ( 1 of 42 , $\sim 3 \%$ ) in the total pool of ure genes present in the metagenome (Table S3). Overall, the dominant ureC variants were most closely related (based on BLASTX) to those of an alphaproteobacterium (Sphingorhabdus flavimaris; 24 of 42 ure C fragments), suggesting that other organisms in the OMZ may compete with ETNP $\mathrm{Ca}$. Scalindua for urea.

UreC of ETNP $\mathrm{Ca}$. Scalindua does not display a close phylogenetic affiliation with that of other lithotrophic organisms, including the ammonia-oxidizing Thaumarchaea and nitrite-oxidizing bacteria (e.g., Nitrospira). Rather, $\mathrm{Ca}$. Scalindua UreC is most closely related (70\% AAI) to UreC of a facultatively anaerobic marine Bacteroidetes bacterium (Raineyella antarctica; [62]) (Fig. 4a, S4). None of the urease-encoding contigs recovered from the SAGs contain marker genes typically used to assess phylogenies (e.g., 16S rRNA gene). However, the largest of these contigs (contig 1 from SAG M13; Fig. 3a) contains a gene encoding the glycolysis protein glyceraldehyde 3-phosphate dehydrogenase (GspA). GspA is conserved among representative genomes from most anammox genera, and phylogenetic analysis placed the M13 GspA in a highly supported clade with that of other Brocadiales, including other $\mathrm{Ca}$. Scalindua species (Fig. S5). Several other genes on this contig also display highest similarity (BLASTP) to anammox-associated Brocadiales. These include two genes encoding $\mathrm{XerC}$, an enzyme mediating site-specific recombination, a process potentially associated with horizontal gene transfer. Tandem repeat sequences, which are often affiliated with recombination, were identified on this contig in five protein-coding genes, all $>1000 \mathrm{bp}$ from the ure genes. Taken together, these data link a potential for urea utilization to ETNP $\mathrm{Ca}$. Scalindua and, given the absence of these genes from other $\mathrm{Ca}$. Scalindua species, raise the possibility that this function was acquired horizontally from a non-anammox organism. The potential for horizontal transfer is supported by the high ANI ( $\geq 98 \%$ ) among ure genes from different SAGs, potentially reflecting recent transfer or strong selection pressure.

The SAG data also support the hypothesis, proposed by Babbin et al. [28], that $\mathrm{Ca}$. Scalindua in AMZs can use cyanate as an ammonium source. Five of the SAGs (Table 1) contain the cynS gene putatively encoding cyanate hydratase (cyanase). Cyanases cleave cyanate to carbamate $\left(\mathrm{H}_{2} \mathrm{NCOO}^{-}\right)$and carbon dioxide and occur in diverse nonanammox bacterial and eukaryotic lineages [63-65], as cyanate is a common by-product of urea degradation and amino acid metabolism. The SAG cynS sequences share 94.5-98.9\% ANI and, in two of the SAGs, are present on $>9 \mathrm{kbp}$ contigs with conserved synteny (Fig. 3b). The SAG cynS is most closely affiliated (82\% AAI) with that of the only other $c y n S$ sequence linked to an anammox bacterium, $\mathrm{Ca}$. Scalindua profunda from sediment. Both $\mathrm{Ca}$. Scalindua 


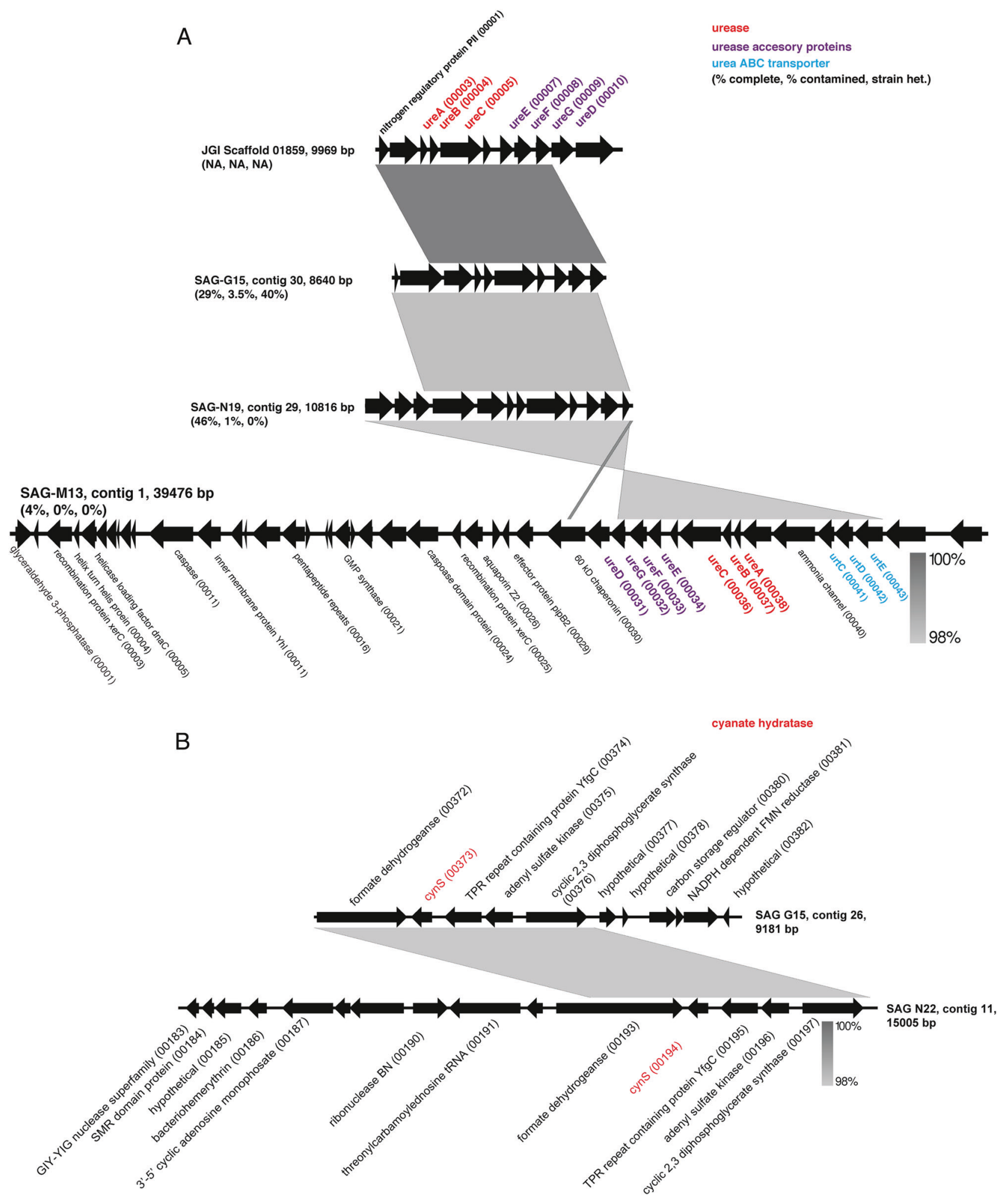

Fig. 3 Gene order and synteny of putative urease (a) and cyanase (b)-encoding contigs identified in SAGs and a metagenomic assembly (JGI Scaffold). Gray shading indicates nucleotide similarity based on BLASTN using the default settings in EasyFig

CynS sequences cluster in a monophyletic clade with those of aerobic nitrite-oxidizing bacteria (Nitrospina) common in the oxycline of AMZ regions (Fig. 4b) [66, 67]. These SAG results link CynS to $\mathrm{Ca}$. Scalindua in AMZs, supporting the work of Babbin et al. [28] showing that cyanate stimulates AMZ anammox. 

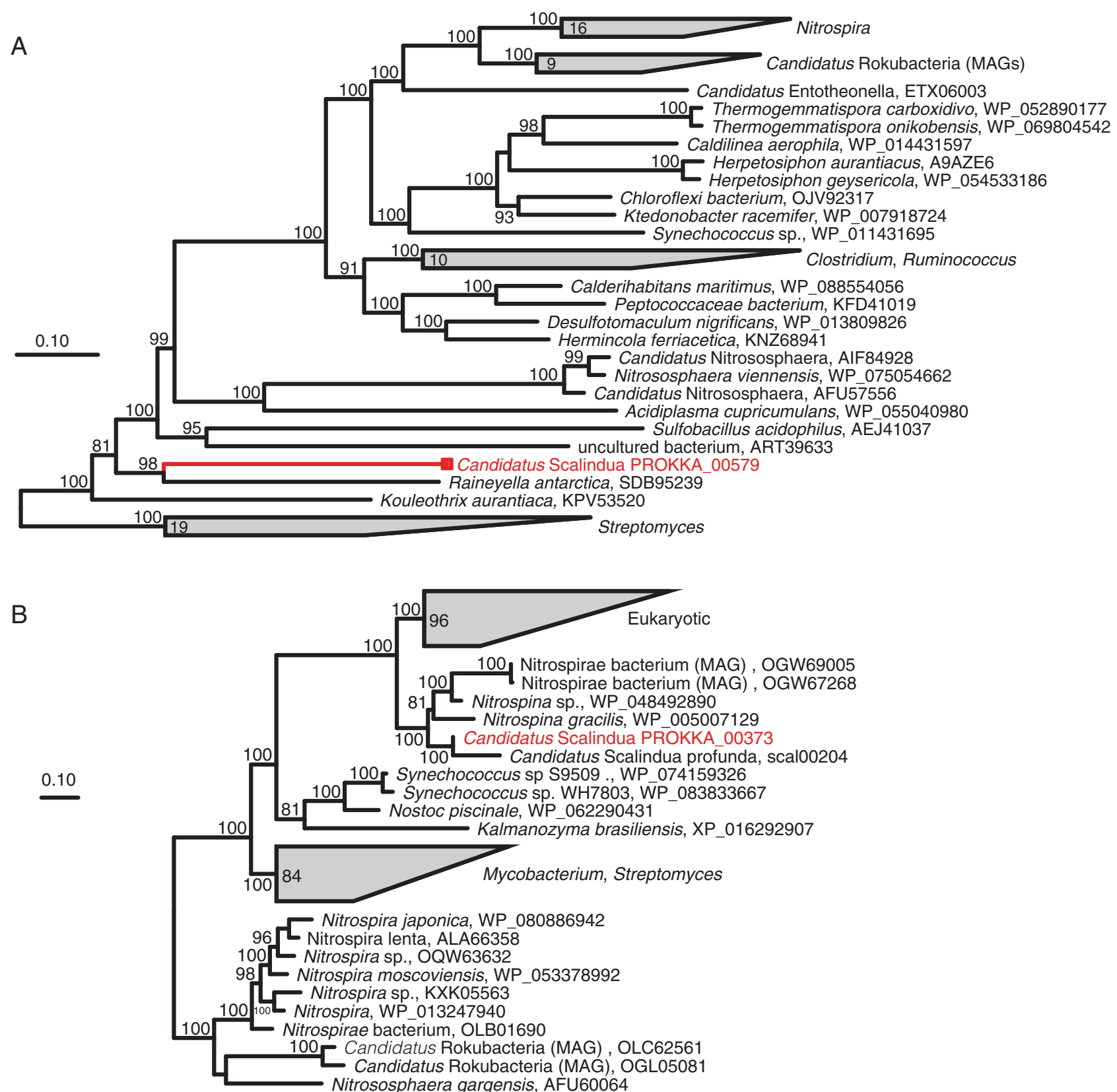

Fig. 4 Maximum likelihood-based phylogeny of the ureC gene encoding the urease alpha subunit (a) and the cynS gene encoding cyanase (b). Representative sequences recovered from ETNP $\mathrm{Ca}$. Scalindua SAGs are highlighted in red, relative to homologs identified

\section{Transcription of alternative nitrogen acquisition pathways by ETNP Ca. Scalindua}

Metatranscriptomics confirmed the activity of key genes of $\mathrm{Ca}$. Scalindua nitrogen-based energy metabolism (Tables S4-S6). We first estimated ETNP $\mathrm{Ca}$. Scalindua's contribution to community transcription by querying metatranscriptome datasets from 5 ETNP sites and multiple depths against a composite SAG amino acid database using a match threshold of $>95 \%$ AAI (above the average as best matches in BLASTP queries of the SAG sequences against the NCBI nr database (black). For both trees, support values are based on approximate likelihood Bayesian ratios ('abayes'), and trees were constructed using the maximum likelihood method

between-SAG AAI of 85\%). The composite database contained sequences from 6 of the most complete SAGs, representing an estimated $\sim 90 \%$ of all homologs shared among the SAG set. This analysis showed that the representation of ETNP $\mathrm{Ca}$. Scalindua transcripts increased dramatically from the base of the oxycline into the AMZ (Fig. 1b, e, h, S2), likely due to an increase in the number of $\mathrm{Ca}$. Scalindua bacteria along this gradient [5]. This is consistent with the increase in anammox rates into the AMZ, although the depth of highest transcript 
representation was below that of highest rates and below the nitrite maximum (Fig. 1c-d).

Transcripts encoding the putative urease and cyanase of ETNP $\mathrm{Ca}$. Scalindua were detected throughout the study area, increasing in representation with depth in a pattern roughly paralleling that of the total ETNP $\mathrm{Ca}$. Scalindua transcript pool (Fig. 1c, f, i, S2). An analysis of metatranscriptome data from the AMZ core $(200 \mathrm{~m})$ at station 6 indicated that over half of all detected ureC transcripts in the AMZ community were most similar to those recovered on ETNP $C a$. Scalindua SAGs (Table S6). Transcripts encoding ABC-type urea transporters (Urt) were also detected (Tables S4 and S5), peaking in proportional representation at 200 meters at Station 6 where urease transcripts were also most abundant (data not shown). In general, urease transcripts were less common than cyanase transcripts. Indeed, cyanases were among the top 40 most transcribed $\mathrm{Ca}$. Scalindua genes at stations with high anammox rates (e.g., station $6 \mathrm{~T}$, Fig. S6). However, both urease and cyanase transcripts were far less abundant than those encoding genes diagnostic of anammox, mainly HZS and $\mathrm{HZO}$, which were commonly among the top 5 most transcribed ETNP $\mathrm{Ca}$. Scalindua proteins (Figures S6 and S7). $\mathrm{CO}_{2}$ fixation in anammox bacteria occurs through the Wood-Ljungdahl pathway, with electrons donated from the oxidation of nitrite to nitrate. Genes diagnostic of this pathway and of nitrite oxidation, notably acs $A$ encoding acetyl coA synthase and narG encoding nitrate/nitrite oxidoreductase respectively, were consistently observed among the $\mathrm{Ca}$. Scalindua transcripts, albeit at low levels (Fig. S7).

The transcript data also provide insight into the importance of other nitrogen-containing compounds in AMZ anammox. Nitric oxide (NO) is a key intermediate in anammox, having been shown in $\mathrm{Ca}$. Kuenenia stuttgartiensis to be condensed with ammonium to form hydrazine [68]. Under non-limiting nitrogen conditions in batch reactors, NirS-type cytochrome cd-1 containing nitrite reductase is implicated as the major route to $\mathrm{NO}$ and is among the most highly expressed proteins [68, 69]. However, while we identified NirS homologs in the SAGs, NirS transcripts were far less abundant than those encoding other anammox proteins, such as HZS and HZO (Figs. 5 and S7). A similar result was observed in a prior study that used the $\mathrm{Ca}$. S. profunda genome to recruit metatranscriptome data from the ETSP AMZ [17]. Interestingly, biochemical investigations of octahaem cytochrome c-containing hydroxylamine/hydrazine oxidoreductase (OCC-HAO) proteins from $\mathrm{Ca}$. Kuenenia stuttgartiensis revealed that one protein (kustc1061) produced NO through the oxidation of hydroxylamine [70]. This protein belongs to a subclade of OCC-HAO proteins named "HZO cluster $2 \mathrm{a}$ " and is phylogenetically distinguishable from other OCC-
HAO/HZO homologs [71]. ETNP SAGs also contain a homolog belonging to HZO cluster 2a (B14_Prokka_00643 in Fig. 5a) and transcripts encoding this protein were consistently more abundant (up to 10-50 times) than those encoding NirS (Fig. 5c). A second HAO homolog, belonging to "cluster 3", has also been predicted to produce NO from nitrite, although this function is not experimentally verified. This homolog (B14_00071 in Fig. 5) was detected in the SAGs and transcribed at a level comparable to that of "HZO cluster 2a" (Fig. 5c). Interestingly, recent work on an anammox bacterium from activated sludge ( $\mathrm{Ca}$. Brocadia sinica) demonstrated that in the absence of canonical enzymes of NO production (nirS, nirK), nitrite was reduced to hydroxylamine, potentially by an OCCHAO protein (although this remains untested), and the resulting hydroxylamine was coupled with ammonium for hydrazine and ultimately $\mathrm{N}_{2}$ production [72]. Our results raise the possibility that hydroxylamine is also a critical intermediate in anammox bacteria from open ocean AMZs. However, the exact role of this substrate and that of associated OCC-HAO proteins in both NO-dependent and independent pathways of ETNP $\mathrm{Ca}$. Scalindua remains speculative.

\section{Evidence for alternative nitrogen use pathways by anammox bacteria in other AMZs}

We screened other AMZ datasets to determine if the potential for urea and cyanase use by anammox bacteria is widespread (Table 2). All screened AMZ datasets contain high numbers of sequences matching ( $>95 \%$ AAI) genes in our composite SAG database (data not shown). Of these, sequences closely related to the urease and cyanaseencoding genes from ETNP $\mathrm{Ca}$. Scalindua were identified in metagenomes and metatranscriptomes from the ETSP AMZ off Chile. These genes were not detected in the ETSP oxycline (Table 2), consistent with the low abundance of $\mathrm{Ca}$. Scalindua at non-AMZ depths in this region [73]. ETNP $\mathrm{Ca}$. Scalindua-like urease genes were also detected in a metagenome from the core of the Arabian Sea AMZ [20], although cyanase genes were not found in this dataset. Close relatives of urease and cyanase genes were not detected in a metatranscriptome from a seasonally anoxic coastal AMZ in Saanich Inlet. These results suggest that the potential for urea and cyanate use for anammox exists in some AMZs, including the major AMZs of the ETSP and Arabian Sea where high anammox rates have been recorded $[46,74,75]$. Also, the failure to detect these genes in some sites (e.g., Saanich Inlet) is not definitive evidence of their absence, as several factors may preclude detection, including the depth of sequence coverage, the proportional abundance of anammox-cells, variability in the timing and depths of sample collection, and potential sequence 
Fig. 5 Phylogeny and transcription of genes potentially mediating nitric oxide formation in anammox. a Octahem cytochrome c hydroxylamine/ hydrazine oxidoreductase (HAO/HZO) phylogeny. Clade nomenclatures are based on a previous phylogenetic assessment of HAO/HZO proteins [71]. Clades with an asterisk indicate subgroups that are new based on the current work. b Cytochrome cd-1 containing nitrite reductase (NirS) phylogeny. Both trees were constructed using maximum likelihood, with support values based on approximate likelihood Bayesian ratios ("abayes"). c Proportional abundance of transcripts encoding the hypothesized hydrazineoxidizing HZO (Panels 1, 4, 7), the hypothesized nitrite-reducing HAO (Panels 2, 5, 8), and the hydroxylamine oxidizing/NO forming $\mathrm{HAO}$ and cytochrome cd-1 containing NirS (panels 3, 6, and 9) at ETNP stations 6 (top row), 7 (middle row), and 3 (bottom row). All scales display activity in $\mathrm{kbp} / \mathrm{Mbp}$ sequenced

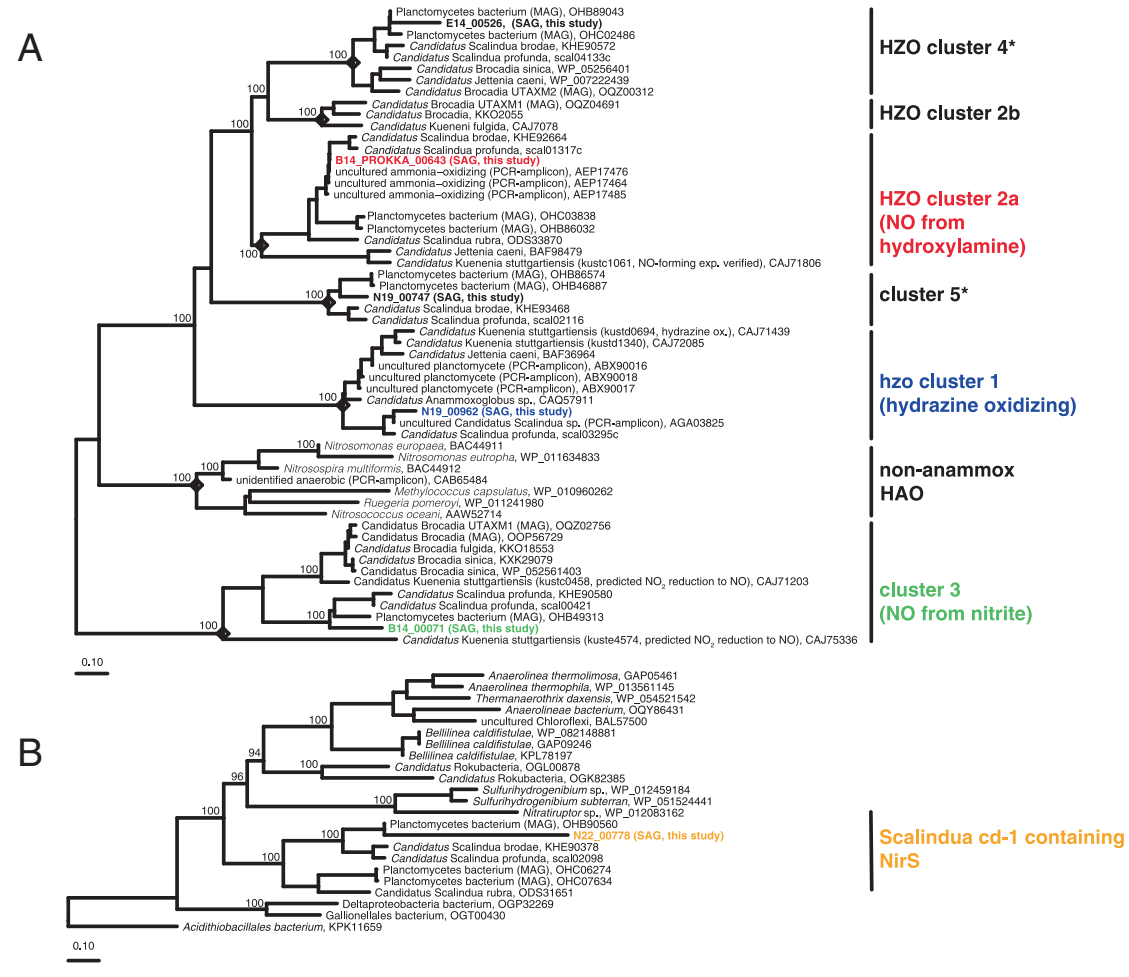

C
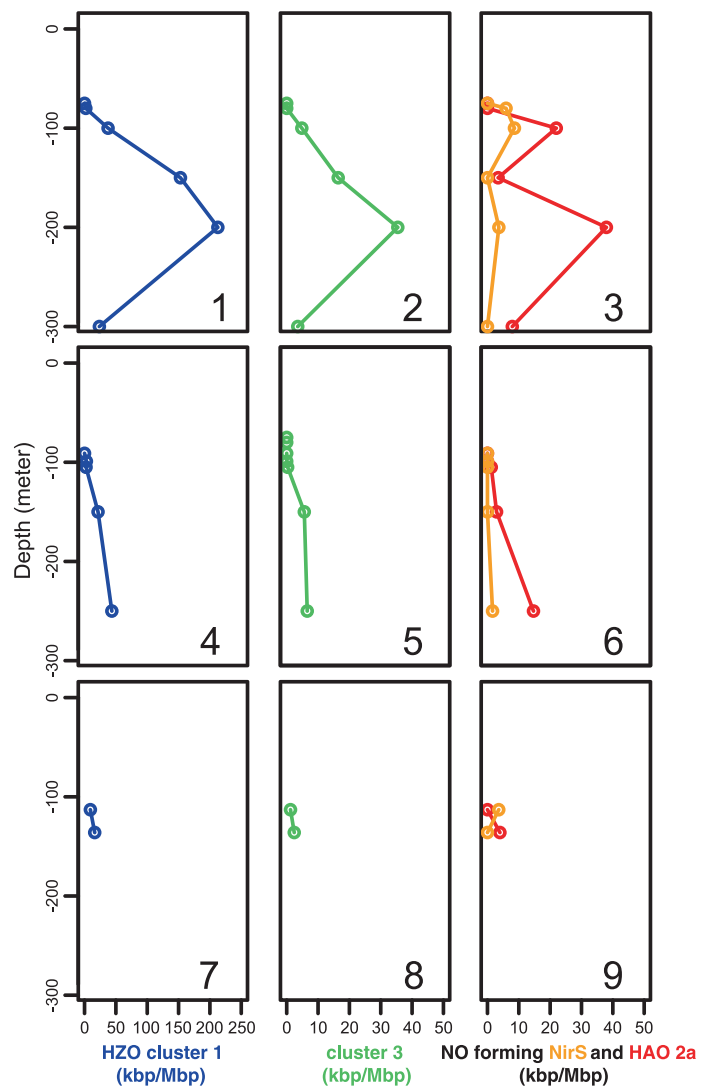

divergence across systems. Further genomic analyses of anammox populations across systems, and perhaps at finer spatial and temporal scales of resolution, will help identify the evolutionary and environmental controls determining the distribution of urease and cyanase genes in marine anammox bacteria. 


\section{Conclusions}

This study provides evidence that anammox bacteria have the potential to degrade both urea and cyanate. At this time, however, it is not possible to determine the exact biochemical role that ureases and cyanases play in ETNP $\mathrm{Ca}$. Scalindua. It is possible that the ammonium liberated by these enzymes is used as an energy substrate for anammox, and therefore contributes to nitrogen loss through $\mathrm{N}_{2}$ production. Alternatively, it is possible that these enzymes serve other functions. Urea and cyanate are common products of protein degradation, and high intracellular concentrations of these substrates may be detrimental to cellular processes. Ureases and cyanases may therefore serve in detoxification, or potentially to cycle ammonium into anabolic pathways. Thus, these enzymes may play a role in the biological retention or recycling, rather than loss, of valuable nitrogen. However, the detection and transcription of urea transporter genes indicates that ETNP $\mathrm{Ca}$. Scalindua likely consumes this organic substrate from the environment, suggesting that urease activity in this organism is not linked exclusively to nitrogen recycling. Furthermore, even recycling will decrease the assimilatory demand for exogenous ammonium and thereby indirectly increase its availability for dinitrogen production.

The consumption of organic nitrogen by aerobic ammonia-oxidizing microorganisms has gained much attention, notably as urease potential occurs in ubiquitous ammonia-oxidizing Thaumarchaeota [76]. Aerobic nitriteoxidizing bacteria of the genus Nitrospira have also been shown to produce ammonia from urea, thereby sustaining co-occurring ammonia-oxidizers that provide nitrite to Nitrospira [26]. However, the contribution of urea to anaerobic pathways of lithotrophic ammonium consumption remains unclear. Indeed, these results are the first report of urease genes in any anammox-capable lineage. Furthermore, while cyanase genes had been reported in anammox bacteria from non-AMZ environments and cyanate shown to support anammox activity in AMZs [28], cyanase genes had not yet been definitively linked to genomes of AMZ anammox bacteria, for example by being found co-localized on a metagenome contig with definitive $\mathrm{Ca}$. Scalindua signatures, or in a genome from a $\mathrm{Ca}$. Scalindua cell/culture. The extent to which ammonium limitation in AMZs selects for organic nitrogen consumption by anammox bacteria remains uncertain, although our results suggest that urea and cyanate use may occur in populations from different AMZs.

Overall, the results expand our knowledge about the metabolic capacity of anammox bacteria and predict mechanisms by which these widespread organisms might supplement direct consumption of free ammonium. Few urea and cyanate measurements have been made for AMZs and data from other regions suggest that concentrations rarely exceed nanomolar levels in the open ocean [77, 78]. While urea and cyanate concentrations were not comprehensively surveyed in this study, our preliminary measurements, coupled with previous measurements of cyanate in Eastern Pacific AMZs [78, 79], suggest levels comparable (urea) or likely lower (cyanate) than those of ammonium. However, it is possible that turnover of these substrates is rapid, particularly at times or depths of lower ammonium levels. Counts of cyanase transcripts in this study were higher than those for urease, suggesting a potential greater role for cyanate as an alternative ammonium source. We caution, however, that the transcript data provide no temporal resolution and may be a poor proxy for actual substrate turnover. Indeed, our knowledge of the temporal variability in AMZ inorganic and organic substrate availability, and in rates of coupled microbial metabolisms, remains limited. Our data suggest only that the potential for direct cyanate and urease use exists for AMZ anammox bacteria. Future experiments should assess the environmental conditions that constrain the use of different ammonium sources. Such experiments should also determine what proportion of the urea and cyanate pools consumed by anammox bacteria are indeed lost through anammox, versus lost through detoxification or incorporation into new biomass. Urea and cyanate have gathered increasing attention within the context of aerobic nitrification, and recent data have indicated that marine populations of aerobic nitrifiers can oxidize ammonia at vanishingly low oxygen levels (nM) that are well within the range under which anammox occurs [80]. Thus, an important question becomes to what extent periodic oxygenation of the anoxic core, and shoaling of the oxycline, change the dynamics of thaumarchaeal ammonium consumption and anammox, and the extent that use of alternative substrates by either group is stimulated or inhibited by these events. Resolving such questions may improve models estimating the role of diverse nitrogen consumption pathways in bulk nitrogen and carbon budgets under AMZ expansion, providing refinements for global marine nutrient cycling.

Acknowledgements This work was supported by the National Science Foundation (1151698, 1558916, 1564559 to FJS and 1416673 to KTK), a European Research Council Advanced grant (OXYGEN, 267233 to BT), the Danish National Research Foundation (DNRF53 to BT), a Community Science Program grant from the U.S. Department of Energy (to FJS and KTK), and the Millennium Science Initiative (IC 120019) and Chilean National Scientific and Technological Research Fund (1161483, supporting MA and OU). The work conducted by the DOE Joint Genome Institute, a DOE Office of Science User Facility, is supported under Contract No. DE-AC02-05CH11231. We are grateful to Neha Sarode for help in sequencing analysis, 
Philipp Hach for help with sample collection, and the captain and crew of the $R / V$ New Horizon for enabling sample collection.

\section{Compliance with ethical standards}

Conflict of interest The authors declare that they have no conflict of interest.

\section{References}

1. Dalsgaard T, Thamdrup B, Farias L, Revsbech NP. Anammox and denitrification in the oxygen minimum zone of the eastern South Pacific. Limnol Oceanogr. 2012;57:1331-46.

2. Thamdrup B, Dalsgaard T, Jensen MM, Ulloa O, Farias L, Escribano R. Anaerobic ammonium oxidation in the oxygen-deficient waters off northern Chile. Limnol Oceanogr. 2006;51:2145-56.

3. Lam P, Lavik G, Jensen MM, van de Vossenberg J, Schmid M, Woebken D, et al. Revising the nitrogen cycle in the Peruvian oxygen minimum zone. Proc Natl Acad Sci USA. 2009;106:4752-7.

4. Ulloa O, Canfield DE, DeLong EF, Letelier RM, Stewart FJ. Perspective: Microbial oceanography of anoxic oxygen minimum zones. Proc Natl Acad Sci USA. 2012; 109:15996-16003.

5. Ganesh S, Bristow LA, Larsen M, Sarode N, Thamdrup B, Stewart FJ. Size-fraction partitioning of community gene transcription and nitrogen metabolism in a marine oxygen minimum zone. ISME J. 2015;9:2682-96.

6. Sabine CL, Feely RA, Gruber N, Key RM, Lee K, Bullister JL, et al. The oceanic sink for anthropogenic $\mathrm{CO}_{2}$. Science. 2004;305:367-71.

7. Thamdrup B, Dalsgaard T, Revsbech NP. Widespread functional anoxia in the oxygen minimum zone of the Eastern South Pacific. Deep-Sea Res Part I. 2012;65:36-45.

8. Tiano L, Garcia-Robledo E, Dalsgaard T, Devol AH, Ward BB, Ulloa $\mathrm{O}$, et al. Oxygen distribution and aerobic respiration in the north and south eastern tropical Pacific oxygen minimum zones. Deep-Sea Res Part I. 2014;94:173-83.

9. Codispoti LA, Brandes JA, Christensen JP, Devol AH, Naqvi SWA, Paerl HW, et al. The oceanic fixed nitrogen and nitrous oxide budgets: Moving targets as we enter the anthropocene? Sci Mar. 2001;65:85-105.

10. Kuypers MM, Lavik G, Woebken D, Schmid M, Fuchs BM, Amann R, et al. Massive nitrogen loss from the Benguela upwelling system through anaerobic ammonium oxidation. Proc Natl Acad Sci USA. 2005;102:6478-83.

11. Kalvelage T, Lavik G, Lam P, Contreras S, Arteaga L, Loscher CR, et al. Nitrogen cycling driven by organic matter export in the South Pacific oxygen minimum zone. Nat Geosci. 2013;6:228-34.

12. Woebken D, Lam P, Kuypers MMM, Naqvi SWA, Kartal B, Strous M, et al. A microdiversity study of anammox bacteria reveals a novel Candidatus Scalindua phylotype in marine oxygen minimum zones. Environ Microbiol. 2008;10:3106-19.

13. De Brabandere L, Canfield DE, Dalsgaard T, Friederich GE, Revsbech NP, Ulloa O, et al. Vertical partitioning of nitrogen-loss processes across the oxic-anoxic interface of an oceanic oxygen minimum zone. Environ Microbiol. 2014;16:3041-54.

14. Nicholls JC, Davies CA, Trimmer M. High-resolution profiles and nitrogen isotope tracing reveal a dominant source of nitrous oxide and multiple pathways of nitrogen gas formation in the central Arabian Sea. Limnol Oceanogr. 2007;52:156-68.

15. Villanueva L, Speth DR, van Alen T, Hoischen A, Jetten MSM. Shotgun metagenomic data reveals significant abundance but low diversity of "Candidatus Scalindua" marine anammox bacteria in the Arabian Sea oxygen minimum zone. Front Microbiol. 2014;5:31.

16. Sonthiphand P, Hall MW, Neufeld JD. Biogeography of anaerobic ammonium-oxidizing (anammox) bacteria. Front Microbiol. 2014;5:399.

17. van de Vossenberg J, Woebken D, Maalcke WJ, Wessels HJ, Dutilh BE, Kartal B, et al. The metagenome of the marine anammox bacterium 'Candidatus Scalindua profunda' illustrates the versatility of this globally important nitrogen cycle bacterium. Environ Microbiol. 2013;15:1275-89.

18. Speth DR, Russ L, Kartal B, Op den Camp HJ, Dutilh BE, Jetten MS. Draft genome sequence of anammox bacterium "Candidatus Scalindua brodae," obtained using differential coverage binning of sequencing data from two reactor enrichments. Genome Announc. 2015;3:e01415-14.

19. Speth DR, Lagkouvardos I, Wang Y, Qian PY, Dutilh BE, Jetten MSM. Draft genome of Scalindua rubra, obtained from the interface above the Discovery Deep Brine in the Red Sea, sheds light on potential salt adaptation strategies in anammox bacteria. Microb Ecol. 2017;74:1-5.

20. Luke C, Speth DR, Kox MAR, Villanueva L, Jetten MSM. Metagenomic analysis of nitrogen and methane cycling in the Arabian Sea oxygen minimum zone. PeerJ. 2016;4:e1924.

21. Zehr JP, Ward BB. Nitrogen cycling in the ocean: new perspectives on processes and paradigms. Appl Environ Microbiol. 2002;68:1015-24.

22. Konieczna I, Zarnowiec P, Kwinkowski M, Kolesinska B, Fraczyk J, Kaminski Z, et al. Bacterial urease and its role in longlasting human diseases. Curr Protein Pept Sc. 2012;13:789-806.

23. Burton SAQ, Prosser JI. Autotrophic ammonium oxidation at low pH through urea hydrolysis. Appl Environ Microb. 2001;67:2952-7.

24. Hallam SJ, Mincer TJ, Schleper C, Preston CM, Roberts K, Richardson PM, et al. Pathways of carbon assimilation and ammonium oxidation suggested by environmental genomic analyses of marine Crenarchaeota. PLoS Biol. 2006;4:520-36.

25. Qin W, Amin SA, Martens-Habbena W, Walker CB, Urakawa H, Devol AH, et al. Marine ammonium-oxidizing archaeal isolates display obligate mixotrophy and wide ecotypic variation. Proc Natl Acad Sci USA. 2014;111:12504-9.

26. Koch H, Lucker S, Albertsen M, Kitzinger K, Herbold C, Spieck E, et al. Expanded metabolic versatility of ubiquitous nitrite-oxidizing bacteria from the genus Nitrospira. Proc Natl Acad Sci USA. 2015;112:11371-6.

27. Marsh KL, Sims GK, Mulvaney RL. Availability of urea to autotrophic ammonium-oxidizing bacteria as related to the fate of C-14- and N-15-labeled urea added to soil. Biol Fert Soils. 2005;42:137-45.

28. Babbin AR, Peters BD, Mordy CW, Widner B, Casciotti KL, Ward BB. Multiple metabolisms constrain the anaerobic nitrite budget in the Eastern Tropical South Pacific. Glob Biogeochem Cycles. 2017;31:258-71.

29. Palatinszky M, Herbold C, Jehmlich N, Pogoda M, Han P, von Bergen $\mathrm{M}$, et al. Cyanate as an energy source for nitrifiers. Nature. 2015;524:105-8.

30. Garcia-Robledo E, Padilla CC, Aldunate M, Stewart FJ, Ulloa O, Paulmier A, et al. Cryptic oxygen cycling in anoxic marine zones. Proc Natl Acad Sci USA. 2017;114:8319-24.

31. Padilla CC, Bristow LA, Sarode N, Garcia-Robledo E, Gómez Ramírez E, Benson CR, et al. NC10 bacteria in marine oxygen minimum zones. ISME J. 2016;10:2067-71.

32. Holmes RM, Aminot A, Kerouel R, Hooker BA, Peterson BJ. A simple and precise method for measuring ammonium in marine and freshwater ecosystems. Can J Fish Aquat Sci. 1999;56:1801-8.

33. Grasshoff K, Ehrhardt M, Kremling K, Almgren T. Methods of seawater analysis. Weinheim: Verlag Chemie; 1983. 
34. Mulvenna PF, Savidge G. A modified manual method for the determination of urea in seawater using diacetylmonoxime reagent. Estuar Coast Shelf S. 1992;34:429-38.

35. Thamdrup B, Dalsgaard T. Production of $\mathrm{N}_{2}$ through anaerobic ammonium oxidation coupled to nitrate reduction in marine sediments. Appl Environ Microbiol. 2002;68:1312-8.

36. Rinke C, Schwientek P, Sczyrba A, Ivanova NN, Anderson IJ, Cheng JF, et al. Insights into the phylogeny and coding potential of microbial dark matter. Nature. 2013;499:431-7.

37. Rinke C, Lee J, Nath N, Goudeau D, Thompson B, Poulton N, et al. Obtaining genomes from uncultivated environmental microorganisms using FACS-based single-cell genomics. Nat Protoc. 2014;9:1038-48.

38. Tsementzi D, Wu JY, Deutsch S, Nath S, Rodriguez-R LM, Burns AS, et al. SAR11 bacteria linked to ocean anoxia and nitrogen loss. Nature. 2016;536:179-83.

39. Wang Q, Garrity GM, Tiedje JM, Cole JR. Naive Bayesian classifier for rapid assignment of rRNA sequences into the new bacterial taxonomy. Appl Environ Microb. 2007;73:5261-7.

40. Magoč T, Salzberg SL. FLASH: fast length adjustment of short reads to improve genome assemblies. Bioinformatics. 2011;27:2957-63.

41. Bankevich A, Nurk S, Antipov D, Gurevich AA, Dvorkin M, Kulikov AS, et al. SPAdes: a new genome assembly algorithm and its applications to single-cell sequencing. J Comput Biol. 2012;19:455-77.

42. Lukashin AV, Borodovsky M. GeneMark.hmm: new solutions for gene finding. Nucleic Acids Res. 1998;26:1107-15.

43. Lagesen K, Hallin P, Rødland EA, Staerfeldt HH, Rognes T, Ussery DW. RNAmmer: consistent and rapid annotation of ribosomal RNA genes. Nucleic Acids Res. 2007;35:3100-8.

44. Parks DH, Imelfort M, Skennerton CT, Hugenholtz P, Tyson GW. CheckM: assessing the quality of microbial genomes recovered from isolates, single cells, and metagenomes. Genome Res. 2015;25:1043-55.

45. Ludwig W, Strunk O, Westram R, Richter L, Meier H, Yadhukumar, et al. ARB: a software environment for sequence data. Nucleic Acids Res. 2004;32:1363-71.

46. Galan A, Molina V, Thamdrup B, Woebken D, Lavik G, Kuypers MMM, et al. Anammox bacteria and the anaerobic oxidation of ammonium in the oxygen minimum zone off northern Chile. Deep-Sea Res Part II. 2009;56:1125-35.

47. Schmid M, Walsh K, Webb R, Rijpstra WI, van de Pas-Schoonen K, Verbruggen MJ, et al. Candidatus "Scalindua brodae", sp. nov., Candidatus "Scalindua wagneri", sp. nov., two new species of anaerobic ammonium oxidizing bacteria. Syst Appl Microbiol. 2003;26:529-38.

48. Seemann T. Prokka: rapid prokaryotic genome annotation. Bioinformatics. 2014;30:2068-9.

49. Jorda J, Kajava AV. T-REKS: identification of Tandem REpeats in sequences with a K-meanS based algorithm. Bioinformatics. 2009;25:2632-8.

50. Yutin N, Puigbo P, Koonin EV, Wolf YI. Phylogenomics of prokaryotic ribosomal proteins. PLoS ONE. 2012;7: e36972.

51. Rodriguez-R LM, Konstantinidis KT. The enveomics collection: a toolbox for specialized analyses of microbial genomes and metagenomes. PeerJ. 2016;4:e1900v1.

52. Contreras-Moreira B, Vinuesa P. GET_HOMOLOGUES, a versatile software package for scalable and robust microbial pangenome analysis. Appl Environ Microbiol. 2013;79:7696-701.

53. Padilla CC, Bertagnolli A, Bristow LA, Sarode N, Glass J, Thamdrup B, et al. Metagenomic binning recovers a transcriptionally active Gammaproteobacterium linking methanotrophy to partial denitrification in an anoxic oxygen minimum zone. Front Mar Sci. 2017;4:23.
54. Kang DWD, Froula J, Egan R, Wang Z. MetaBAT, an efficient tool for accurately reconstructing single genomes from complex microbial communities. PeerJ. 2015;3:e1165.

55. Babbin AR, Keil RG, Devol AH, Ward BB. Organic matter stoichiometry, flux, and oxygen control nitrogen loss in the ocean. Science. 2014;344:406-8.

56. Lam P, Kuypers MMM. Microbial nitrogen cycling processes in oxygen minimum zones. Annu Rev Mar Sci. 2011;3:317-45.

57. Thrash JC, Temperton B, Swan BK, Landry ZC, Woyke T, DeLong EF, et al. Single-cell enabled comparative genomics of a deep ocean SAR11 bathytype. ISME J. 2014;8:1440-51.

58. Konstantinidis KT, Tiedje JM. Genomic insights that advance the species definition for prokaryotes. Proc Natl Acad Sci USA. 2005;102:2567-72.

59. Rodríguez-R LM, Konstantinidis KT. Bypassing cultivation to identify bacterial species. Microbe. 2014;9:111-8.

60. Mobley HLT, Island MD, Hausinger RP. Molecular biology of microbial ureases. Microbiol Rev. 1995;59:451-80.

61. Pearson MM, Sebaihia M, Churcher C, Quail MA, Seshasayee AS, Luscombe NM, et al. Complete genome sequence of uropathogenic Proteus mirabilis, a master of both adherence and motility. J Bacteriol. 2008;190:4027-37.

62. Pikuta EV, Menes RJ, Bruce AM, Lyu Z, Patel NB, Liu Y, et al. Raineyella antarctica gen. nov., sp. nov., a psychrotolerant, damino-acid-utilizing anaerobe isolated from two geographic locations of the Southern Hemisphere. Int J Syst Evol Microbiol. 2016;66:5529-36.

63. Kamennaya NA, Chernihovsky M, Post AF. The cyanate utilization capacity of marine unicellular cyanobacteria. Limnol Oceanogr. 2008;53:2485-94.

64. Kamennaya NA, Post AF. Characterization of cyanate metabolism in marine Synechococcus and Prochlorococcus spp. Appl Environ Microbiol. 2011;77:291-301.

65. Rocap G, Larimer FW, Lamerdin J, Malfatti S, Chain P, Ahlgren NA, et al. Genome divergence in two Prochlorococcus ecotypes reflects oceanic niche differentiation. Nature. 2003;424:1042-7.

66. Fussel J, Lam P, Lavik G, Jensen MM, Holtappels M, Gunter M, et al. Nitrite oxidation in the Namibian oxygen minimum zone. ISME J. 2012;6:1200-9.

67. Zaikova E, Walsh DA, Stilwell CP, Mohn WW, Tortell PD, Hallam SJ. Microbial community dynamics in a seasonally anoxic fjord: Saanich Inlet, British Columbia. Environ Microbiol. 2010;12:172-91.

68. Kartal B, Maalcke WJ, de Almeida NM, Cirpus I, Gloerich J, Geerts W, et al. Molecular mechanism of anaerobic ammonium oxidation. Nature. 2011;479:127-30.

69. Kartal B, Keltjens JT. Anammox biochemistry: a tale of heme c proteins. Trends Biochem Sci. 2016;41:998-1011.

70. Maalcke WJ, Dietl A, Marritt SJ, Butt JN, Jetten MSM, Keltjens JT, et al. Structural basis of biological NO generation by octaheme oxidoreductases. J Biol Chem. 2014;289:1228-42.

71. Schmid MC, Hooper AB, Klotz MG, Woebken D, Lam P, Kuypers MMM, et al. Environmental detection of octahaem cytochrome c hydroxylamine/hydrazine oxidoreductase genes of aerobic and anaerobic ammonium-oxidizing bacteria. Environ Microbiol. 2008;10:3140-9.

72. Oshiki M, Ali M, Shinyako-Hata K, Satoh H, Okabe S. Hydroxylamine-dependent anaerobic ammonium oxidation (anammox) by "Candidatus Brocadia sinica". Environ Microbiol. 2016;18:3133-43.

73. Stewart FJ, Ulloa O, DeLong EF. Microbial metatranscriptomics in a permanent marine oxygen minimum zone. Environ Microbiol. 2012;14:23-40.

74. Bulow SE, Rich JJ, Naik HS, Pratihary AK, Ward BB. Denitrification exceeds anammox as a nitrogen loss pathway in the 
Arabian Sea oxygen minimum zone. Deep-Sea Res Part I. 2010;57:384-93.

75. Ward BB, Devol AH, Rich JJ, Chang BX, Bulow SE, Naik H, et al. Denitrification as the dominant nitrogen loss process in the Arabian Sea. Nature. 2009;461:78-81.

76. Alonso-Saez L, Waller AS, Mende DR, Bakker K, Farnelid H, Yager PL, et al. Role for urea in nitrification by polar marineArchaea. Proc Natl Acad Sci USA. 2012;109:17989-94.

77. Solomon CM, Collier JL, Berg GM, Glibert PM. Role of urea in microbial metabolism in aquatic systems: a biochemical and molecular review. Aquat Microb Ecol. 2010;59:67-88.
78. Widner B, Mordy CW, Mulholland MR. Cyanate distribution and uptake above and within the Eastern Tropical South Pacific oxygen deficient zone. Limnol Oceangr. 2018;63:S17792.

79. Widner B, Mulholland MR, Mopper K. Cyanate distribution and uptake in North Atlantic coastal waters. Environ Sci Technol Lett. 2016;3:297-302.

80. Bristow LA, Dalsgaard T, Tiano L, Mills DB, Bertagnolli AD, Wright JJ, et al. Ammonium and nitrite oxidation at nanomolar oxygen concentrations in oxygen minimum zone waters. Proc Natl Acad Sci USA. 2016;113:10601-6. 